sounds inaudible by certain ears, and physiological investigations, such as the duration of muscular motion and sea-sickness, discussed in bis Croonian lecture, all of which further attest his wide interests. His skill as a technician was very great and is frequently commented upon by his contemporaries.

Another phase of Wollaston's activities is reflected in his twelve years' secretaryship of the Royal Society, of which he was later interim president, in 1820. He received many honours, an outstanding one being his election as one of the eight foreign associates of the Paris Academy of Sciences. He was a benefactor to the Geological Society and for more than a hundred years that Society has commemorated him by the annual award of the medal which bears his name, the highest which it can bestow.

Wollaston had many close friends among scientific workers at home and abroad and not a few have recorded their deep admiration for him both as an investigator and as a man. "Berzelius for one was an enthusiastic admirer. In some of his letters indeed the great Swede writes of
Wollaston in almost extravagant terms of praise. Faraday in 1821 said that 'His character and talents have raised him to be a patron and protector of science. All men look to his opinion and judgment with respect'." "Some of his more intimate friends have left eloquent testimony to his lovable qualities as a man"; "of the great pleasure he always derived from the company of children and young people" ; of his modesty "but also upon the indignation he would display when faced with the slightest deviation from honesty and truth, or any departure from justice". Miss Edgeworth sums up an estimate of him in the words "He confirms... the opinion I have always held, that great talents are always connected with warm affections-with what is commonly called heart".

Sir Frederick Gowland Hopkins acknowledged his indebtedness for information on aspects of Wollaston's scientific work to Mr. L. F. Gilbert, of University College, London, who is engaged in compiling a biography of Wollaston and suggested, in the first instance, the erection of the memorial.

W. T. Gordon.

\title{
Yale North India Expedition
}

\section{By G. E. Hutchinson, Osborn Zoological Laboratory, Yale University}

A LL the members of the expedition of the A Yale North India Expedition 1932-33, under the leadership of Dr. H. de Terra, having returned to Yale University more than a year ago, it is now possible to give a brief preliminary account of some of the results of the field work achieved.

In our geographical studies we were fortunate in securing the services of the distinguished Indian topographer, Khan Sahib Afraz Cul Khan, who surveyed 4,600 square miles of imperfectly mapped country on the western borders of Tibet. Dr. de Terra, using this new map in conjunction with his geological studies, has been able to recognise the eastern continuation of the Karakorum on to the Tibetan plateau ${ }^{1}$. The orographic axis of the range undergoes a bend from north-west-south-east to west-east, so that the Karakorum clearly fails to make its supposed connexion with the Transhimalaya. The re-entrant, clearly marked in all the component ranges of the Karakorum, is represented throughout the whole of the mountain belt between the Ganges and Central Asia, and corresponds to that of the Gondwanaland mass.

Wadia had previously demonstrated the overthrusting of the southern Himalaya towards Gondwanaland, and this has now been confirmed on a larger scale, embracing the north and central portions of the range. The main geotectonic structure of the entire mountain belt is seen to consist of the southward shifting of successive belts of folding towards India, beginning in the Middle Cretaceous and lasting until to-day. As in the case of the Alps, the overthrusts have moved mainly across 'flysch' and 'molasse' rocks and in many places are connected with basis volcanics in part of submarine origin. In the late Pleistocene, the Pir Panjal Range was added to the Tertiary mountain belt, and various piedmont levels on the Tibetan plateau indicate that uplifts have been of recurrent occurrence throughout the Pleistocene.

Dainelli's idea of four Himalayan glaciations in the Quaternary has in the main been confirmed, but the detailed study of interglacial deposits leads to somewhat different results from those of earlier workers. In relation to the studies carried out on the Pleistocene deposits of the region, our discoveries of human artefacts, though few and fragmentary, acquire a special significance. The most interesting find was a flake of Levallois type discovered in a lake deposit near Srinagar, Kashmir. Another important site, also yielding specimens representing an early palæolithic flake culture, was discovered near Chitta in the Salt Range. A detailed report on this material by Mr. and Mrs. C. Hawkes is now in the press ${ }^{2}$.

Mr. G. E. Lewis, palæontologist of the expedition, made a very large collection of Tertiary mammals, principally in the Salt Range and Simla Hill States. Among the rich material of Primates, one form, Ramapithecus brevirostris, Lewis, described in a recent preliminary communication $^{3}$, deserves special mention. This Upper Siwalik form, represented by a right maxilla and premaxilla, appears in its parabolic dental arcade, small transverse canine alveolus, absence of diastemata, small incisors, high palate and slight prognathism, to approach more closely to the Hominidæ than any previously discovered Tertiary 
ape. The presence of such a form in these beds on one hand, and of early palæolithic cultures in the North Indian Pleistocene on the other, inspires the not too remote hope that very primitive hominids may one day be found in this region.

A preliminary note on some of my limnological work has already appeared in NATURE ${ }^{4}$. It is as yet scarcely possible to evaluate the zoogeographical significance of the large collection of fishes and invertebrates brought back. Two points may, however, be briefly noticed.

On the basis of his geomorphological studies, Dr. de Terra has reconstructed ${ }^{\mathbf{1}}$ the Tertiary drainage pattern of the western part of the Tibetan plateau. A number of rivers ran from west to east, one of them occupying the present valley of the Upper Indus. It is difficult to resist the conclusion that a similar pattern extended farther north, the Tarim basin draining into the Hwang-ho. If this hypothesis be accepted, it is possible to give a rational explanation of the distribution of the most characteristic group of Central Asiatic fishes, the Schizothoracinæ. At present this sub-family occurs in at least twelve major river systems and numerous small closed basins. My field studies appear to indicate that the most primitive genus Schizothorax is most abundant in relatively quiet water, while the species found in the most rapid streams belong to the most specialised genera. This is to be expected if we suppose that the subfamily was distributed as the Tertiary drainage pattern suggests, from a centre in the present Karakorum, then a region of comparatively late mature relief, the truly torrenticolous genera such as Dyptichus not evolving until the progressive uplifts had provided a system of suitable habitats for such forms. Further problems of distribution are raised by these and other fish, but it would be out of place to discuss them until the entire collection has been studied by Dr. S. L. Hora.

A second zoogeographical result emerges from a study of the insects of high altitudes. In examining the collection of terrestrial Heteroptera, I have been much impressed by the high proportion of endemic forms; at least half the species are peculiar to the higher parts of the Himalaya and western Tibet. This contrasts strikingly with the situation presented by the Pamirs ${ }^{5}$, where the fauna though richer is much less peculiar. In spite of the intense Quaternary glaciation of the betterknown parts of western Tibet, it seems impossible to avoid the conclusion that a large part of the Tibetan Plateau was unglaciated, forming, as Meinertzhagen ${ }^{6}$ has emphasised, a biological island in which species and even genera were differentiated, and from which the glaciated regions were recolonised.

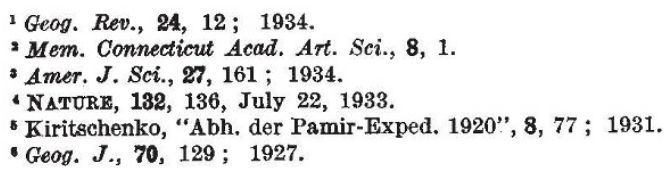

\section{The Mersey Road Tunnel}

$\mathrm{T}$ HE tunnel constructed under the Mersey for vehicular traffic between Liverpool and Birkenhead, which was opened by H.M. the King on July 18, is a great engineering construction possessing many interesting features. It is the largest sub-aqueous tunnel yet constructed, its ventilation installation is on an elaborate scale and the architectural treatment of its entrances and buildings have received as much consideration as the construction of the tunnel itself. The consulting engineer for the scheme is Sir Basil Mott, Bt., with whom has been associated Mr. J. A. Brodie, for many years the city engineer of Liverpool, while Mr. H. J. Rowse is the architect of the ventilation buildings. Others who have been called in to advise on various matters include Prof. P. G. H. Boswell, Prof. Douglas Hay and Prof. J. S. Haldane.

A railway tunnel beneath the Mersey has been in use since the 'eighties of last century, but the ever-increasing stream of passengers and vehicles crossing the river by the ferries has long shown the need for further facilities. In 1925 the local authorities obtained from Parliament the Mersey Tunnel Act, and under this was set up the statutory body, the Mersey Tunnel Joint Committee, the controlling authority for the construction of the tunnel. The general plan of the project includes a main tunnel for four lines of traffic from Old Hay- market, Liverpool, to Chester Street, Birkenhead, 3,751 yards long, with two branch tunnels for two lines of traffic, one on either side of the river, bringing the total length of roadway up to 5,064 yards. It is estimated that the tunnel will have a capacity of 4,150 cars per hour moving at 20 m.p.h., the time taken for a vehicle to pass along the tunnel being $6 \frac{1}{2}$ minutes. Side-walks are provided on both sides of the roadways for the staff, but in normal circumstances the tunnel will not be used by pedestrians.

The portion of the tunnel of greatest interest is that beneath the river bed. Here the bottom of the tunnel is $170 \mathrm{ft}$. below high water, while above the top is an average thickness of $\mathbf{3 0 - 3 5} \mathrm{ft}$. of rock, gravel and clay. The rock is red triassic sandstone. Circular in section, this portion of the tunnel has external and internal diameters of $46 \frac{1}{4} \mathrm{ft}$. and $44 \mathrm{ft}$. respectively. It is thus the largest sub-aqueous tunnel in the world, the Rotherhithe Tunnel, London, having a diameter of $30 \mathrm{ft}$. and the Holland Vehicular Tunnels, New York, a diameter of $29 \frac{1}{2} \mathrm{ft}$.

Begun in 1925, two pilot headings were first driven from each of the two shafts sunk on each side of the river and the workings met almost exactly in the middle of the river bed on April 3, 1928. The divergence of line, length and level was very slight. These pilot headings were then 